Proceedings

\title{
Determination of Particles and Carcinogenic Compounds Emitted by Combustion of Diesel and Diesel:Biodiesel Blends ${ }^{+}$
}

\author{
Samantha Arteaga-Del Angel *, Brenda L. Valle-Hernandez and Violeta Mugica-Alvarez \\ Department of Basic Sciences, Universidad Autónoma Metropolitana-Azcapotzalco, San Pablo Ave. 180, \\ Azcapotzalco, Mexico City 02200, Mexico; brendalizvh@atmosfera.unam.mx (B.L. V.-H.); \\ vma@correo.azc.uam.mx (V.M.-A.) \\ * Correspondence: samy_ada@hotmail.com \\ + Presented at the 2nd International Research Conference on Sustainable Energy, Engineering, Materials and \\ Environment (IRCSEEME), Mieres, Spain, 25-27 July 2018.
}

Published: 7 November 2018

\begin{abstract}
Among the main pollutants emitted into the atmosphere by diesel combustion are the particles. Most of the studies suggest that the greatest impact on health by the particles is caused by some of the organic compounds such as the polycyclic aromatic hydrocarbons, which are highly toxic and carcinogenic compounds. Some of the strategies that are being implemented to mitigate these harmful particles emissions are the use of alternative fuels, such as biodiesel. In this research, the characterization of six fuels (diesel and five biodiesel, obtained from different raw materials) was carried out. Diesel:Biodiesel blends were prepared at 5, 10 and $20 \%$ of biodiesel on proportion to the diesel (B5, B10 and B20). Additionally, B100 was analyzed for some biodiesels. The particles emitted by the combustion of the different fuels were sampled and their concentration was determined. The organic compounds were extracted from the particles by ultrasound-assisted extraction and subsequently the polycyclic aromatic hydrocarbons (PAHs) were determined by gas chromatography coupled to mass spectrometry (GC-MS). In this study, it was observed that the use of biodiesel decreases the emission of particle concentration, but it is not significant. In the case of the concentrations of carcinogenic compounds (PAHs), the B20 biodiesel blends emissions had a statistically significant reduction compared to diesel emissions.
\end{abstract}

Keywords: combustion; diesel; biodiesel; polycyclic aromatic hydrocarbons

\section{Introduction}

The particles [1] are among the main pollutants emitted into the atmosphere by the combustion of diesel. Most studies suggest that the greatest health impact from particles is caused by highly toxic and carcinogenic compounds, such as some organic compounds (especially polycyclic aromatic hydrocarbons) [2]. The United States Agency for Toxic Substances and the Registry of Diseases has considered 17 of them as priority pollutants based on their toxicological profile [3]. Some strategies to mitigate the emissions of harmful particles are the use of alternative fuels, such as biodiesel, which is less toxic than diesel, free of sulfur and aromatics, which is obtained from vegetable oils, waste oils or animal fats [4]. 


\section{Materials and Methods}

\subsection{Obtaining Fuels}

Diesel used in this research was obtained from a PEMEX gas station in Mexico City, which meets the specifications established in NOM-016-CRE-2016. The commercial biodiesel was provided by the company "Biofuels de México S.A. de C.V". The other four biodiesel were obtained in the laboratory through the transesterification process using different raw materials; the "biodiesel UAM" was obtained from used oil from the UAM Azcapotzalco cafetery, the "biodiesel Santa Fe" from oil of a Mexican snacks inn, the "biodiesel de Pollo" with chicken fat, the "biodiesel Rosticeria" from chicken oil of a rotisserie. The biodiesel was prepared to different blends: B5 (5\% biodiesel, 95\% diesel), B10 ( $10 \%$ biodiesel, $90 \%$ diesel), B20 (20\% biodiesel, 80\% diesel) and in some cases B100 (100\% biodiesel). Obtaining a total number of 18 mixtures of the different fuels.

\subsection{Sampling}

Particles sampling was carried out in the laboratory, implementing a sampling protocol. Particles emitted from the combustion of $1 \mathrm{~mL}$ of each fuel mixture were collected, all the samples were carried out in duplicate. Fiberglass filters previously conditioned at $300{ }^{\circ} \mathrm{C}$ for $12 \mathrm{~h}$ and subsequently stabilized at $24{ }^{\circ} \mathrm{C}$ and relative humidity $<23 \%$.

\subsection{Determination of Particles}

The particles mass was determined by the weight difference using an analytical balance (resolution of $0.1 \mathrm{mg}$ ). Subsequently, the average of each sample, the standard deviation and the coefficient of variation were determined. The concentration in $\mathrm{mg}$ of particles $/ \mathrm{mL}$ of fuel was reported.

\subsection{Determination of Carcinogenic PAHs}

Organic compounds were extracted by ultrasound-assisted extraction (UAE) [5]. Polycyclic aromatic hydrocarbons (PAHs) were analyzed by gas chromatography-mass spectrometry (GC-MS, Agilent Technologies, Santa Clara, CA, USA). PAHs parent ions were quantified by their deuterated PAHs. Twenty PAHs were determined in the studied samples, including the 17 priority PAHs of the EPA [6].

\section{Results and Discussion}

\subsection{Particles}

Table 1, shows the results of the concentration of particles emitted by each fuel and their mixtures. Blends of B20 had lower particle concentration compared to blends of B5 and B10. This pattern could be observed in all types of the studied biodiesel; in the case of the filters with the diesel samples, it was obtained the highest concentrations of all fuel samples. These results show that the use of biodiesel reduces the amount of particles emitted.

Table 1. Concentration of particles emitted by the combustion of each fuel (mg/mL).

\begin{tabular}{ccccccc}
\hline $\begin{array}{c}\text { Blends } \\
\text { Fuels }\end{array}$ & $\begin{array}{c}\text { Biodiesel } \\
\text { Comercial }\end{array}$ & $\begin{array}{c}\text { Biodiesel } \\
\text { UAM }\end{array}$ & $\begin{array}{c}\text { Biodiesel } \\
\text { Santa Fe }\end{array}$ & $\begin{array}{c}\text { Biodiesel } \\
\text { Pollo }\end{array}$ & $\begin{array}{c}\text { Biodiesel } \\
\text { Rosticería }\end{array}$ & Diesel \\
\hline B5 & $85.2 \pm 2.2$ & $82.5 \pm 3.5$ & $90.1 \pm 5.0$ & $92.1 \pm 0.6$ & $92.1 \pm 4.9$ & \\
B10 & $79.1 \pm 4.2$ & $77.8 \pm 4.5$ & $84.3 \pm 2.7$ & $88.4 \pm 2.7$ & $89.6 \pm 0.7$ & \\
B20 & $56.7 \pm 3.2$ & $70.4 \pm 1.8$ & $74.6 \pm 0.9$ & $70.7 \pm 1.8$ & $73.6 \pm 0.1$ & $95.4 \pm 0.1$ \\
B100 & $5.4 \pm 0$ & - & - & $5.7 \pm 0$ & - & \\
\hline
\end{tabular}

\subsection{Polycyclic Aromatic Hydrocarbons}

20 PAHs were determined, based on the 17 PAHs that the EPA considers as priorities. 
In Figure 1 is possible to see the results of the total PAHs of all studied mixtures. The blends of the used cooking oils (biodiesel UAM and biodiesel Santa Fe) showed the highest concentrations of PAHs. Whereas, the blends of biodiesel from rotisserie and chicken fat presented the lowest concentrations. The mixtures of B20 had lower concentration of total PAHs in three of five of the studied biodiesel, only in the blends with biodiesel obtained from animal fat, the B20 mixtures had a higher concentration of PAHs than those in the B5 blends.

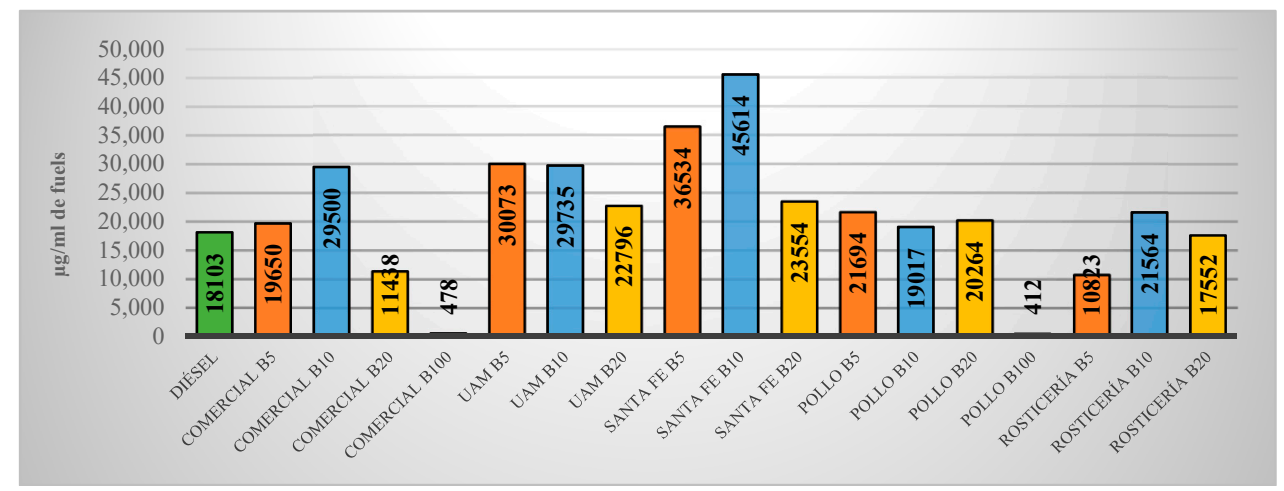

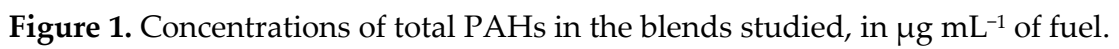

Figure 2 shows the concentrations of carcinogenic PAHs. The highest concentrations of carcinogenic PAHs were B5 and B10 blends of the biodiesel Santa Fe. On the contrary, the lower concentrations of carcinogenic PAHs were observed in the B5 biodiesel rosticeria and the B20 comercial. The concentrations presented from diesel combustion were lower than most biodiesel blends; the only blends with lower concentration than diesel were the B5 rosticeria, B20 rosticeria, B20 UAM, B5 comercial and B20 comercial.

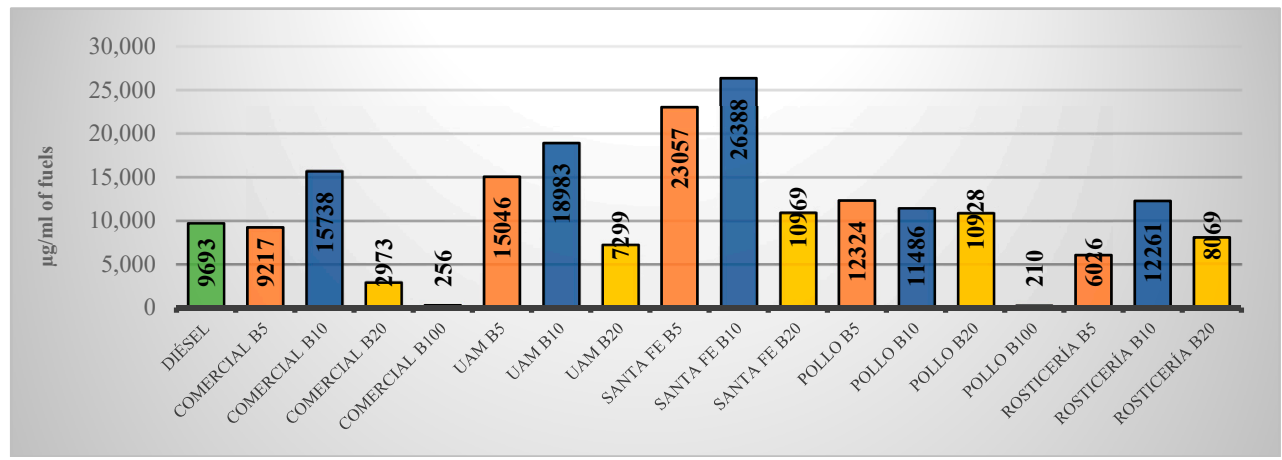

Figure 2. Concentrations of carcinogenic PAHs in the blends studied in $\mu g \mathrm{~mL}^{-1}$ of fuel.

\section{Conclusions}

- A reduction in particle concentration was observed when biodiesel blends are used. Although, this difference was not statistically significant $(p>0.05)$.

- In the concentrations of carcinogenic PAHs a higher concentration was observed in the B10 mixtures. However, there was only significant difference between B20 and diesel blends $(p<0.05)$.

- The use of biodiesel does not make a significant difference in the emission of particles, but when using blends of B20 compared to diesel, the concentrations of carcinogenic PAHs decrease in most of the used biodiesel.

- Therefore, the use of B20 blends would be recommended as a measure to reduce the emissions of carcinogenic compounds into the atmosphere. This recommendation is given by tests at laboratory level so it is necessary to perform tests with a diesel engine to observe the validity of the results obtained. 
Acknowledgments: CONACYT is thanked for the grant awarded to Samantha Arteaga-Del Angel and Infrastructure Project number 271115.

\section{References}

1. Lloyd, A.C.; Cackette, T.A. Diesel Engines: Environmental Impact and Control. J. Air Waste Manag. Assoc. 2001, 51, 809-847.

2. Gil, L.; Adonis, M. Polycyclic Aromatic Hydrocarbon Levels and Mutagenic Activities of Organic Extracts from Airborne Particles in Santiago de Chile. Sage J. 1996, 5, 155-164.

3. Agencia para Sustancias Tóxicas y el Registro de Enfermedades (ATSDR). Agencia de los Estados Unidos para las Sustancias Toxicas y el Registro de Enfermedades; ATSDR: Atlanta, GA, USA, 1995.

4. Basha, S.A.; Gopal, K.R.; Jebaraj, S. A review on biodiesel production, combustion, emissions and performance. Renew. Sustain. Energy Rev. 2008, 13, 1628-1634.

5. United States Environmental Protection Agency. Compendium of Methods for the Determination of Toxic Organic Compounds in Ambient Air, 2nd ed.; Crude Petroleum and Liquid Petroleum Products by Hydrometer Method; Office of Research and Development, National Risk Management Research Laboratory, Center for Environmental Research Information: Cincinnati, OH, USA, 1999.

6. United States Environmental Protection Agency. Polycyclic Aromatic Hydrocarbons (PAHs); Office of Solid Waste: Washington, DC, USA, 2008.

(C) 2018 by the authors. Licensee MDPI, Basel, Switzerland. This article is an open access article distributed under the terms and conditions of the Creative Commons Attribution (CC BY) license (http://creativecommons.org/licenses/by/4.0/). 